\title{
Knowledge attitude and practice on iodine deficiency disorder and iodine level in salt in retail and vendors among the rural population in south India: A community based observational and descriptive study
}

\author{
Senthilvel Vasudevan ${ }^{\mathrm{a}, *}$, Sumathi Senthilvel ${ }^{\mathrm{b}}$, Jayanthi Sureshbabu ${ }^{\mathrm{c}}$ \\ a Department of Pharmacy Practice, College of Pharmacy, King Saud Bin Abdulaziz University for Health Sciences, Riyadh, Saudi Arabia \\ ${ }^{\mathrm{b}}$ Amrita College of Nursing, Amrita Vishwa Vidyapeetham (Deemed University), Kochi, Kerala, 682041, India \\ ${ }^{\mathrm{c}}$ Department of Community Medicine, Pondicherry Institute of Medical Sciences, Pondicherry, 605 014, India
}

\section{A R T I C L E I N F O}

\section{Keywords:}

Iodine deficiency disorders

Rural population

Knowledge

Attitude

Practice

\begin{abstract}
A B S T R A C T
Background: An Iodine deficiency disorder causes a major problem of brain damage in human beings and it is a major public health problem in India and worldwide.

Objective: To assess the knowledge, attitude and practice regarding use of iodized salt among households and to find the iodine content level at the traders and retail vendors in the rural study areas of the Marakkanam block. Methods: A community based descriptive study on IDD was conducted in Marakkanam block population, Tamil Nadu with a sample size of 1233 individuals.

Results: The goiter prevalence was high in female gender when compared with male and higher goiter prevalence rate was found in the lower economic group. Among 1233 individuals, 796 (64.6\%) were heard about iodized salt, whereas 437 (35.4\%) were not heard about it. Only 294 (23.8\%) of the respondents were aware that iodine deficiency caused some disease or health problem. Total of 525 salt sample packets was collected at the traders' level and it that $99 \%$ of the salt samples were iodized but most of them weren't adequately iodized. Conclusion: From our present study, we have concluded that nearly one fourth of the study population didn't have enough knowledge about IDD and its consequences. To eliminate the lack of their knowledge on IDD by conducting an effective awareness programs. Try to eradicate IDD related diseases in the study areas by encouraging the community people to use iodized salt, encourage the retail shop owners, vendors to sell an adequate iodized salt packets and by reducing the cost of the iodized salt packets through Government of Tamilnadu or private Non - Governmental Organizations.
\end{abstract}

\section{Introduction}

Iodine deficiency disorders (IDD) causes a major problem of brain damage in human beings. ${ }^{1}$ It has been recognized as a major public health problem in India. Not only India, it is a public health problem of worldwide as per WHO. ${ }^{2}$ Most of the consequences of IDD aren't visible but these defects are to be curable. IDD causes goiter, hypothyroidism, cretinism, intellectual disability, psychomotor defects, hearing and speech impairment, abortion and stillbirths. In India, 1.2 billion people at the risk of IDD and nearly 264 million people at high risk. India has the largest number of children born vulnerable to IDD. In 2009, nearly $71 \%$ adequately iodized salt covered in India from Yadav et al. ${ }^{3,4}$ Nowadays, $92 \%$ of the Indian population consumes iodized salt. In the last two decades, India has saved 4 billion IQ points by adequate salt iodization. $\mathrm{UNICEF}^{5}$ has pointed out that iodine deficiency can cause IDD problem, mental retardation. Globally, $86 \%$ of the population has accessed the iodized salt. The highest coverage of iodized salt with $91 \%$ and $87 \%$ have accessed iodized salt in South Asia and East Asia \& the Pacific respectively was given by United Nations Children's Fund (UNICEF) data. ${ }^{6}$

IDD causes the diseases like goiter, cretinism, hypothyroidism, brain damage, abortion, still birth, mental retardation, hearing and speech impairment in human population Hetzel et al. ${ }^{7}$ Among 130 countries have reported the data on IDD in the 2006, IDD was a public health problem in 47 countries in worldwide from De Benoist et al. ${ }^{8}$ Every year approximately pregnant women and newborns are at the risk of IDD in India by 9 and 8 million respectively. These based on the household level IDD Evaluation survey in 2009 and extrapolated to the total

\footnotetext{
* Corresponding author. Department of Pharmacy Practice, College of Pharmacy, King Saud Bin Abdulaziz University for Health Sciences, Riyadh, Saudi Arabia. Tel.: + 966572455123 .

E-mail addresses: vasudevans@ksau-hs.edu.sa (S. Vasudevan), sumathinursing80@gmail.com (S. Senthilvel), jayanthisuresh1@gmail.com (J. Sureshbabu).
} 
population estimate from the 2011 census United Nations International Children's Emergency Fund ${ }^{9}$; India Census. ${ }^{10}$ The iodine requirement in up to 12 months, children (2-6 years), school children (7-12 years), adults (above 12 years) and pregnant and lactating women are $50 \mu \mathrm{g}$, $90 \mu \mathrm{g}, 120 \mu \mathrm{g}, 150 \mu \mathrm{g}$ and $200 \mu \mathrm{g}$ respectively. ${ }^{11}$ A global review study by Andersson et al. ${ }^{12}$ has mentioned as the number of iodine deficiency countries have been decreased from 110 to 47 in the year 2007. In a study, Pandev CS et al. ${ }^{13}$ have been stated that the overall goiter rate was $13.5 \%$ and consumption of adequate iodized salt by households was $18.2 \%$ only in the state of Tamil Nadu. These types of KAP studies aren't available in the rural areas of Tamil Nadu state. Moreover a survey showed that 29 districts of Tamilnadu the endemic was found in 18 districts as per revised policy guidelines of Government of India. So, we have decided to find out the status of knowledge, attitude and practice about IDD and iodine content in household and in the retail shops in our study population. The main objectives of our present study were to assess the knowledge, attitude and practice regarding use of iodized salt among households in this study population and to find iodine content at the traders and retail vendors in the study rural area.

\section{Methods}

Study area: The study was conducted in the field practice area of the Pondicherry Institute of Medical Sciences (PIMS) Rural Health Center, Anachikuppam which administrated under the Marakkanam block of Villupuram district, Cuddalore Zone, Tamil Nadu, South India. In Villupuram district, 2229 acres of area is used as saltspan and total salt production of 80,283 tonnes, in which 79,383 tonnes is under registered and 900 tonnes is unregistered was given by UNDP United Nations Team for Recovery Support. ${ }^{14}$

Study period: The study was conducted from 01st - 26th February 2012.

Study design: The study design of our present study was community-based, observational and descriptive study.

Study population: The study population consisted of all individuals residing in the villages under the field practice area of the PIMS RHC, Anachikuppam in the Marakkanam Development Block of Villupuram district, Tamil Nadu. Marakkanam has located $52 \mathrm{Km}$ towards East from Villupuram and $125 \mathrm{Km}$ from Chennai towards North as shown in Fig. 1. The field practice area includes 16 villages.

Sample size: A total of 1233 households belonging to 8 villages were covered in this study. 2830 individuals who were available at the time of interview in these households were examined goiter by those who were posted and trained students of the seventh semester under graduate medical students posted in the Department of Community Medicine under the supervision of Community Medicine faculties in a community based observational study by Vasudevan et al. ${ }^{15}$ One responsible person from each household were selected and interviewed with them regarding knowledge, attitude and practice regarding use of iodized salt.

Sampling methodology: Eight villages (Kil Puthupattu, Koonimedu, Chettikuppam, Anumandai, Kil Pettai, Parichamedu, Alapakkam, Ora Nai) were randomly selected from 16 villages in the field practice area of the PIMS RHC as shown in Fig. 2. Out of total 1356 households in the 8 selected villages, 1233 households in which the responsible person of the particular family those who were available at the time of house-to-house survey and they were included in this study. In this present study, we have included both the gender those who are residing in the above mentioned villages for at least 1 year and above, with all age groups those who were the head of the family or a responsible person of the concerned household.

Data collection: Data collection was done over a period of 15 days by the trained medical seventh semester students those who were posted under the research - oriented medical education program and were worked in $24 \times 7 \mathrm{~h}$ basis for one full month was given by Vasudevan. ${ }^{16}$ Before data collection the medical students were trained

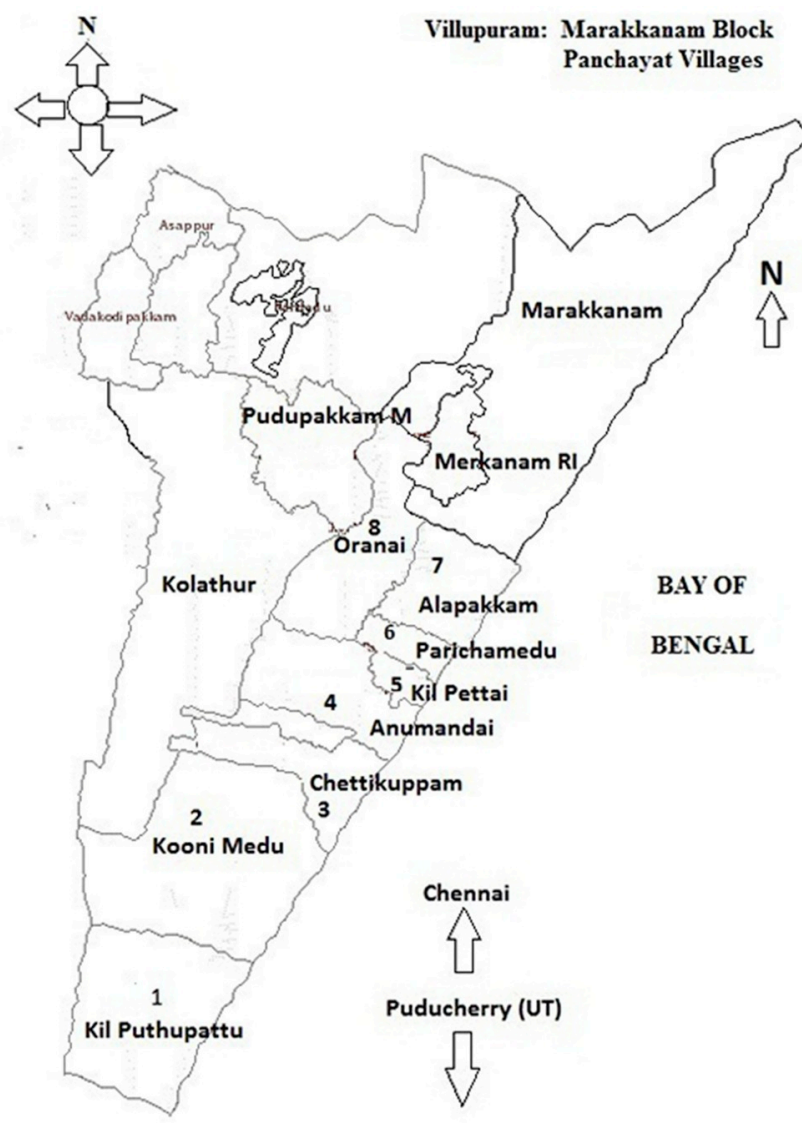

Fig. 1. Distribution of Panchayat villages in the Marakkanam Block in Villupuram District.

properly in all aspects by the faculties of Department of Community Medicine. The participants were explained with the local TAMIL language regarding the purpose and importance of our study at the time of data collection. The consenting individuals were only included in our present study. Data were collected under my guidance and supervision, and with the help of inters those who were posted at that time of study conducted in the Department of Community Medicine and Post Graduate students of Community Medicine. Support of the village leaders, representatives was sought prior to the start this survey in each of these villages. By house to house survey in the selected villages and the data collection was done by using a pre-designed and pre-tested questionnaire. The study questionnaire was used to collect the following data under three topics:

i) Socio-demographic characteristics: First part was used to document name of village, household number, name of the family members, age, gender, religion, educational level, source of drinking water and the income of the family.

ii) KAP on use of iodized salt: Data on the knowledge, attitude and practices towards Iodized salt was collected by using a structured questionnaire.

iii) Iodine level of salt at consumer and trader levels: The household salts were tested for qualitatively on spot with MBI kit provided by GOI/UNICEF and made available through the Assistant Director (Nutrition) Puducherry. Iodine content was estimated in the household salt by MBI kits as given by MBI KITS international. The iodine concentration was recorded categorically as 0 , $0.1-14.9,>15 \mathrm{ppm}$. In that, $0 \mathrm{ppm}$ was taken as not iodized; $0.1-14.9$ ppm was as sufficiently iodized and $\geq 15 \mathrm{ppm}$ was adequately iodized. During the house to house survey, all the traders of salt in these villages were identified and one salt packet of all 


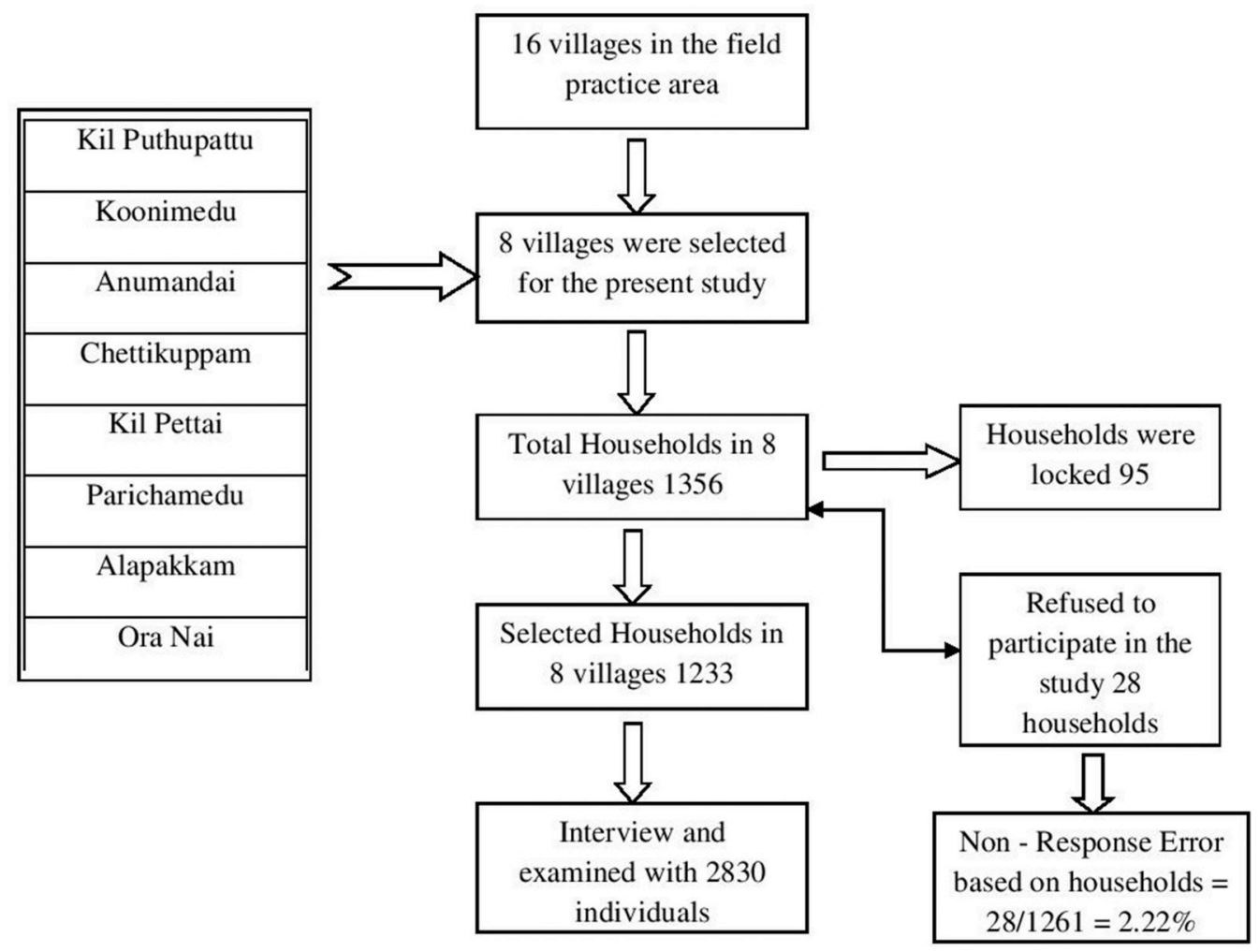

Fig. 2. Flowchart of the selected villages in the study area/population.

available brands (both powdered and crystalline in packed as well as loose forms) was procured. The same was tested or the iodine level using the rapid testing kits. The testing was done in the following method: The kits consisted of $10 \mathrm{ml}$ bottles containing a stabilized starch-based solution. One drop of the solution was dripped on a teaspoon of salt from the household. Production of purple coloration indicated that iodine was present. The colour was matched with the graded colour plate on the testing kit and the appropriate level of iodine was recorded. In cases where there is suspicion of alkalinity in the salt sample, a recheck solution, supplied in the kit was used. A drop of this solution is applied, followed by the test solution and the colour change matched with the colour plate. Similarly, salt Iodine content was estimated in the retail shop and vendor salts by using MBI Kit by MBI KITS International ${ }^{32}$ and UNICEF MICS. ${ }^{17}$

Statistical Software Used: Data were compiled by using Microsoft Excel 2010 and analyzed by the statistical software SPSS 20.0 version.

Statistical Analysis: Qualitative variables were expressed as number and percentages.

\section{Results}

In this present knowledge, attitude and practice study, we have visited totally 1356 households in the 8 selected villages and 2830 individual data were collected from 1233 households. So, the non-response rate based on households was $2.2 \%$. The overall goiter prevalence was found as $8.0 \%$. The goiter prevalence was high in female gender when compared with male and higher goiter prevalence rate was found in the lower economic group of the study population. The prevalence of goiter was more found $12.4 \%$ in lower socio-economic class. From 1233 households, we have recruited and included 1233 respondents those who was the head of the family (husband)/responsible person (his wife) of the particular house and others were excluded. Get the answers of the structured questionnaire related to knowledge, awareness and practice from the all 1233 respondents and as follows:

Knowledge about the study population: Of the 1233 respondents included in the survey for Knowledge, Attitude and Practices on Iodized salt from the 1233 surveyed households, 824 (66.8\%) had knowledge about goiter, $796(64.6 \%)$ had heard about iodized salt, whereas 437 (35.4\%) had not heard about it. Among 796 respondents who were having the knowledge of Iodized salt, the major source of information was Television 651 (81.8\%), Shopkeepers 189 (23.7\%) and inscription of Iodized salt on the salt packets $19 \%$.

Attitude about the study population: Among 1233 respondents, only $294(23.8 \%)$ of the respondents were aware that iodine deficiency caused some disease or health problem, another 80 (6.2\%) said that it doesn't cause any deficiency condition, whereas 859 (70\%) responded as "don't Know". Of the 294 respondents, 16 (5.4\%) were knew that iodine deficiency causes some disease or health problem, $180(61.2 \%)$ were knew that it affects the thyroid followed by $44(15.0 \%)$ mental problems, $34(11.6 \%)$ growth retardation and $20(6.8 \%)$ respondents said hypertension could be caused as a result of iodine deficiency.

Practice about the study population: Among 1233 study households/respondents, most 857 (69.5\%) of the respondents did not know if the iodized salt was beneficial, 359 (29.1\%) have felt that it was beneficial and $17(1.4 \%)$ respondents felt that it was of no benefit to use iodized salt. Most $768(62.3 \%)$ respondents were using iodized salt in their day to day life and it was good for their health. $28(2.3 \%)$ respondents felt that the iodized salt is clean as compared to non-iodized salt. It is interesting to note that $48(3.9 \%)$ respondents were aware of the importance of iodized salt in brain development in children, physical growth of children. Another 12 (3.1\%) were pregnant and using iodine content salt in the day to day life. 44 (11.5\%) individuals, though aware that iodized salt was beneficial and using in their food, but couldn't tell what benefit it could give.

Most 960 (77.9\%) of the respondents did not know if there was any disadvantage in using iodized salt, $244(19.8 \%)$ of the 1233 respondents felt that use of iodized salt was of no disadvantage. 29 (2.3\%) 
respondents felt that there was some disadvantage in using iodized salt. Among 29 respondents, said as disadvantages by 20 (69.0\%) with include high cost, followed by $9(31.0 \%)$ were hypertension, diabetes, kidney disease and obesity. The local grocery stores were the major source of procurement of both the powered salt 1179 (95.6\%) and crystalline salt $830(67.3 \%)$ among the households. It is interesting to note that $149(20.2 \%)$ of crystalline salts used in these households were obtained from the PDS (Public distribution System).

The traditional ambulant vendor selling crystalline salt is the source of that type of salt in 56 (7\%) households. Majority 1176 (95.4\%) of the households used containers with lid for storing the salt. Whereas, 18 (1.5\%) used containers without lid and another 27 (2.2\%) households did not transfer the salt to any container, but stored it in its original packet itself. Others included $8(0.7 \%)$ households storing the salt in gunny bags and another $4(0.3 \%)$ using paper to wrap the salt. Majority $1080(87.6 \%)$ of the households stored the salt inside cabinets, another $47(3.8 \%)$ stored on the table. In $76(6.2 \%)$ households, the salt was placed just above the stove itself. $76(6.2 \%)$ respondents knew that they weren't using iodized salt. Only $543(44.0 \%)$ of the respondents knew that they were using iodized salt. A significant 614 (49.8\%) number of them were not aware of whether the salt used in their houses was iodized.

\section{Discussion}

The KAP survey among one respondent from each of the 1233 households revealed that 437 (35.4\%) were not aware of iodized salt and 796 (64.6\%) had heard about it. Similar type of result had been mentioned in a study by Roy et al. ${ }^{18}$ that more than half of the study populations were unaware about iodized salt. Similarly, in another one study by Joseph et al. ${ }^{19}$ has mentioned that the Iodized Salt Coverage Study 2010, across eight states reported that among people surveyed, $57.8 \%$ were aware of iodized salt, and $55 \%$ of these had iodized salt in the household. Among 769 respondents the major source of information through television $650(81.7 \%)$, Shopkeepers $120(15.1 \%)$ and inscription of Iodized salt on the salt packets (2.5\%). Only 294 (23.8\%) of the respondents were having the aware of iodine deficiency caused some disease or health problems, another $80(6.2 \%)$ believed that it does not cause any deficiency condition, whereas 859 (70\%) responded as don't Know. Of the 294 respondents, 180 were aware that it affects the thyroid followed by mental problems. Similar types of results were given by $\mathrm{Kapil}^{20}$ and impaired mental function was given by Government of India. ${ }^{21}$ The study population have had the knowledge about the IDD causes due to iodine deficiency through the major source of information was Television even though they didn't ready to buy the iodized salt for their family usage due to their poverty. A review study by Yadav et al. ${ }^{3,4}$ showed that a significant in the iodine deficiency in the pregnant women in India in that study the respondents said hypertension could be caused as a result of iodine deficiency. In 2010, the Iodized Salt Coverage Study reported that $62 \%$ of the people surveyed knew iodine deficiency results in goiter, with the highest $81.7 \%$ awareness in Orissa and the lowest 39.7\% in Andhra Pradesh. Overall, $35.4 \%$ of the people knew that iodine deficiency causes less mental development and diminished intelligence was reported by Mohapatra et $\mathrm{al}^{22}$

Over $80 \%$ respondents in tribal a tribal region of Orissa did not have knowledge of IDD and were not aware of salt iodization by Bulliyya et al. ${ }^{23}$ Less than $10 \%$ in a similar region of Orissa had correct knowledge of the cause of goiter and use of iodized salt. A study by Choudhury and Baruah ${ }^{24}$ in Assam showed that $90 \%$ of household were consumed iodized salt and very quiet high $90 \%$ knowledge in the Rani area in Assam. Most 70\% of the respondents did not know if the iodized salt was beneficial, 359 (29\%) felt that it was beneficial with another 17 (1\%) respondents believing that it was of no benefit. The benefits as per the respondents included good for their health $62 \%$, salt is clean as compared to non-iodized salt 7\%, importance of iodized salt in brain development in children, physical growth of children (4\%) and another $3 \%$ were aware that its use is good during pregnancy. $29(2 \%)$ respondents felt that there were some disadvantages in using iodized salt, they being high cost by Choudhury and Baruah ${ }^{24}$ and followed by hypertension from India Census ${ }^{10}$; mental retardation from India Census $^{10}$; Joseph el. al. ${ }^{19}$; diabetes, kidney disease and obesity. Of the 999 households using powdered salt, only $20(2 \%)$ of it were found to be inadequately iodized, including 16 samples with no iodine at all. A very high proportion $70 \%$ of the crystalline salts used by the 793 households was found to be inadequately iodized. This includes $57 \%$ with no iodine at all. Overall, it was seen that 172 (13.9\%) households don't use adequately iodized salt in the surveyed villages. Whereas in one study related to iodine deficiency disorder by Pandav et al. was found that the household adequately iodized salt ( $\geq 15 \mathrm{ppm}$ ) consumption was $18.2 \%$. In Marakkanam area saltspan are more and manufacturing of volume of salt also more, but that is the non - iodized salt only. These salt bags are transported to the branded companies then only adequate iodine is to be added in that. The National Family Health Survey- $2^{25}$ was conducted in $1998-99$ and revealed that $62.7 \%$ of the families were consuming salt without iodine content and $8.1 \%$ had less than 15 ppm. Kapil et al. ${ }^{20}$ has revealed that a higher percentage (71.1\%) of the families was consuming cooking salt with iodine content $15 \mathrm{ppm}$ or more. The proportion of households using adequately iodized salt in Tamil Nadu has increased from $30.6 \%$ (NFHS-3) to $41.9 \%$ in 2010 from Micronutrient Initiative Summary Report. ${ }^{26}$ In one report, the use of adequately iodized salt was used $72 \%$ and $41 \%$ in both Urban and Rural areas respectively by India Country Report (2013). One study across India had shown the proportion of iodized salt coverage declined from $49 \%$ in 1998-99 National Family Health Survey $-2^{27}$ and subsequently plateauted at $51 \%$ in $2005-06$ was given by National Family Health Survey. ${ }^{28}$ The control of IDD programme was lost five crucial years due to this change in legislation. The current $91 \%$ of household level coverage of iodized salt in India, of which $71 \%$ per cent is adequately iodized salt, is a big achievement. Some studies were showed that the rural households had increased across in all the states in India from $27 \%$ to $47.2 \%$ compared to NFHS - 3 Government of India ${ }^{21}$; National Family Health Survey - 2 (2000). Whereas a study on household used of iodized salt in rural area by Roy et al. ${ }^{18}$ was showed that $62.5 \%$ of households were consuming adequately iodized salt.

The Coverage Evaluation Survey in 2009 covering all the States and Union Territories of India collected from 22,604 mothers/caretakers of children aged 12-23 months and 22,984 mothers who delivered during 12 months prior to the survey. Overall, $71.1 \%$ of the households were using cooking salt which was iodized at the recommended level of $15 \mathrm{ppm}$ or more was reported in the National Family Health Survey -2 (2000). In the present study, 21 brands of salt packets were collected that included 14 powdered and 7 crystal salt packets were collected from 22 traders from 8 villages. Of the 14 powdered salts, 2 (14\%) were found to be inadequately iodized (0.1-14.9 ppm), with 1 sample with no iodine $(0 \mathrm{ppm})$ at all. Whereas, a higher proportion $4(57.1 \%)$ of the crystalline salts were found to be inadequately iodized, with all of them having no trace of iodine present. A study was also assessed Salt at the trader's level in seven states and Union Territories. In our present study, a total of 525 salt samples were collected from the traders' level in the study areas. Out 525 salt samples (packets), 520 (99.0\%) of the salt samples were iodized. But, among 520 samples 150 (28.8\%) weren't adequately iodized. In that, $370(71.2 \%)$ of the salt samples have an iodine content of $15 \mathrm{ppm}$ and more. Similar type of results arrived from a study by $\mathrm{Kapil}^{20}$ has mentioned that in all the states more than $70 \%$ of the salt samples had an iodine content of $15 \mathrm{ppm}$ and more. Not iodized $(0 \mathrm{ppm})$ salt used in the study area was found as $0 \%$. But, in the surveyed Marakkanam Block rural areas of population have purchased and used only the lower cost salt in their day to day life due to economic problem of the family and that salt packets have contained low level (in adequate) of iodine content of (0.1-14.9 ppm). A study by Kumar ${ }^{29}$ has had revealed that the quality of iodized salt assessed at various levels in 
West Bengal reported 'satisfactory' iodine content at $84.3 \%$ wholesalers, $74.3 \%$ retailers and $71.2 \%$ consumer's level. Mishra et al. ${ }^{30}$ have reported that $54.3 \%$ of salt samples only found to be adequate and $39 \%$ salt samples were found with inadequate iodine at retail shops of Panchmahal district in Gujarat, India. By this study, we have to create awareness about iodine content level in their using household salt and the importance of iodine by demonstrating in front of them "How much iodine content in their using household salt by using MBI kits?". We were creating awareness and educated the rural community people about IDD, its importance, how to stored, where to stored and its effects in children, adults and in pregnant lady in the study population were have given by Vasudevan et al. ${ }^{15}$

\section{Conclusion}

From our present study, we have concluded that nearly one fourth of the study population didn't have enough knowledge about IDD and its consequences in the study areas of Marakkanam block. To eliminate the lack of their knowledge on IDD and to reduce their burden by conducting an effective awareness programs in the community level. Try to eradicate IDD related diseases in the study areas by encouraging the community people to use iodized salt, encourage the retail shop owners, vendors to sell adequate iodized salt packets and by reducing the cost of the iodized salt packets through Government of Tamilnadu or private Non - Governmental Organizations.

\section{Recommendation to the further study}

This type of knowledge, attitude and practice studies weren't conducted/available in the rural areas of Marakkanam block, Tamil Nadu state, South India. So, this type KAP studies are very essential one in the remaining parts of the block and try to eliminate IDD and its problems in the community level.

\section{Conflicts of interest}

The authors are declared that they aren't having any conflicts of interest.

\section{Ethical standards}

This study was done with prior oral permission from the head of the village administrated officer and from the head of the particular family. Our study is a KAP study only, so there are no ethical issues. ${ }^{31}$

\section{Funding}

There was no funding received from any institution or an organization or an agency to conduct this study. No incentive to be given to any of the study participants.

\section{Acknowledgement}

The authors are very thankful to the Director-Principal, HOD of the Department of Community Medicine for his support and guidance and those who are involved in the study including ANMs, Interns, PGs and other office staffs.

\section{Appendix A. Supplementary data}

Supplementary data to this article can be found online at https:// doi.org/10.1016/j.cegh.2018.10.002.

\section{References}

1. World Health Organization. Iodine Status Worldwide: WHO Global Database of Iodine
Deficiency. Geneva: WHO; 2004:1-58 Available on: http://apps.who.int/iris/ bitstream/10665/43010/1/9241592001.pdf.

2. World Health Organization. Assessment of iodine deficiency disorders and monitoring their elimination: a guide for programme managers - third Edition. Page No: 1-108. Available on: http://apps.who.int/iris/bitstream/10665/43781/1/ 9789241595827_eng.pdf; 2007.

3. Yadav K, Pandav CS, Karmarkar MG. Adequately iodized salt covered seventy-one percent of India in 2009. International council for control of iodine deficiency disorders. IDD Newsletter. 2011;39(2):1-20 Available on: http://www.iccidd.org/cm_ data/IDD-NL-2011-2.pdf.

4. Yadav K, Srivastava R, Badhal S, Palanivel C, Pandav CS, Karmarkar MG. Iodine nutrition of pregnant women in India: evidence of significant iodine deficiency. Indian J Med Specialties. 2011;3:49-54. https://doi.org/10.7713/ijms.2012.0011 Published online on 24/11/2011.

5. UNICEF: Guidance on the Monitoring of Salt Iodization Programmes and Determination of Population Iodine Status: for every child. 1-19. Available on: https://www.unicef.org/nutrition/files/Monitoring-of-Salt-Iodization.pdf.

6. UNICEF Data. Update: monitoring the situation of children and women: current status \& progress. Available on: https://data.unicef.org/topic/nutrition/iodinedeficiency/\#; 2018.

7. Towards the global elimination of brain damage due to iodine deficiency - a global program for human development with a model applicable to a variety of health, social and environmental problems. In: Hetzel BS, Delange F, Dunn JT, Ling J, Venkatesh Mannar, Pandav CS, eds. International Council for the Control of Iodine Deficiency Disorders. New Delhi: Oxford University Press; 2004. Available from: http://www.ign.org/cm_data/2004_Hetzel_Towards_the_global_elimination_of_brain_ damage.pdf.

8. De Benoist B, McLean E, Andersson M, Rogers L. Iodine deficiency in 2007: global progress since 2003. Food Nutr Bull. 2008;29:195-202. https://doi.org/10.1177/ 156482650802900305 PMID: 18947032.

9. United Nations International Children's Emergency Fund. Coverage Evaluation Survey, All India Report New Delhi: Ministry of Health and Family Welfare, Government of India; 2009 Available on: http://www.unicef.org/india/health.html.

10. India Census. Provisional Population Totals Paper I of 2011 India Series 1. New Delhi: The Office of Registrar General and Census Commissioner. Ministry of Home affairs, Government of India; 2011. 2011. Available from: http://censusindia.gov.in/2011prov-results/data files/india/Final PPT 2011 chapter3.pdf.

11. World Health Organization. Recommended Iodine Levels in Salt and Guidelines for Monitoring Their Adequacy and Effectiveness. Geneva: Nutrition Unit, Division of Food and Nutrition, WHO; 1996:1-12 Available on: http://apps.who.int/iris/bitstream/ 10665/63322/1/WHO_NUT_96.13.pdf?ua $=1$.

12. Andersson M, de Benoist B, Rogers L. Epidemiology of iodine deficiency: saltiodisation and iodine status. Best Pract Res Clin Endocrinol Metabol. 2010;24(1):1-11. https://doi.org/10.1016/j.beem.2009.08.005 PMID:20172466.

13. Pandev CS, Yadav K, Srivastava R, Pandav R, Karmarkar MG. Iodine deficiency disorders (IDD) control in India. Indian J Med Res. 2013;138:418-433 PMID: 24135192

14. UNDP United Nations Team for Recovery Support. Project to Improve the Socio-economic Conditions of Salt Workers in Tamil Nadu. Vrutti Livelihood Resource Centre; 2007:1-63 Available on: http://www.vrutti.org/images/documents/publications_ Final\%20Report\%20on\%20Salt\%20Study\%20-\%20Vrutti\%20-\%205\%20Mar\%2008. pdf.

15. Vasudevan S, Priyankaraj CK, Senthilvel S, Sureshbabu S. Iodine deficiency disorder in rural population: a community based observational study on prevalence in the coastal area of Tamil Nadu state, South India. Indian J Public Health Res \& Dev. 2018;9(2):100-105. https://doi.org/10.5958/0976-5506.2018.00264.4.

16. Vasudevan $S$. Biostatistics teaching to the undergraduate medical students through research-oriented medical education posting program in a Teaching Medical Institute in Coastal Area of Pondicherry: an experience of a biostatistician. $J$ Pharm BioAllied Sci. 2016:78-79. https://doi.org/10.4103/0975-7406.171693.

17. UNICEF MICS: Multiple Indicator Cluster Survey Manual: Salt Iodization Testing. Available on: http://mics.unicef.org/files?job $=$

W1siZiIsIjIwMTUvMDQvMDEvMDEvNTQvNDYvNDg0L01JQ1M0X01hbnVhbF9 TYWx0X0lvZG16YXRpb25fVGVzdGluZy5kb2MiXV0\&sha = fcf15c0b84bff475.

18. Roy R, Charturvedi M, Agrawal D, Ali H. Household use of iodized salt in rural area. $J$ Fam Med Prim Care. 2016;5(1):77-81. https://doi.org/10.4103/2249-4863.184628 PMCID: PMC4943155.

19. Joseph M, Kaushik S, Dey S, Dutt S, Jha RK. Reaching the rural poor in India with iodized salt: the micronutrient Initiativess iodized salt coverage study 2010. IDD Newsletter. 2011:6-7.

20. Kapil U. Health consequences of iodine deficiency. Sultan Qaboos Univ Med J. 2007;7(3):267-272 PMCID: PMC 3074887

21. Government of India. IDD \& Nutrition Cell, Ministry of Health \& Family Welfare. Revised Policy Guidelines on National Iodine Deficiency Disorders Control Programme. Revised Edition: IDD \& Nutrition Cell, Directorate General of Health Services. Ministry of Health \& Family Welfare; 2006 Available on: http://pbhealth.gov.in/Revised\%20Policy \%20Guidelines\%20Govt.\%20of\%20India.pdf.

22. Mohapatra SSS, Bulliyya G, Kerketta AS, Geddam JJB, Acharya AS. Elimination of iodine deficiency disorders by 2000 and its bearing on the people in a district of Orissa, India: a knowledge-attitude- practices study. Asia Pac J Clin Nutr. 2001;10(1):58-62. https://doi.org/10.1046/j.1440-6047.2001.00203.x.

23. Bulliyya G, Dwibedi B, Mallick G, Sethy PG, Kar SK. Determination of iodine nutrition and community knowledge regarding iodine deficiency disorders in selected tribal blocks of Orissa, India. J Pediatr Endocrinol Metab. 2008;21(1):79-87 PMID: 18404976.

24. Choudhury D, Baruah R. Knowledge and practices regarding use of iodized salt and 
iodine deficiency disorder among the population of Rani, Kamrup (R), Assam. Indian J Basic Appl Med Res. 2016;5(4):467-474.

25. National Family Health Survey_2. NFHS - 1998-99: India. New Delhi: International Institute for Population Sciences (IIPS) and ORC Macro, Mumbai, Ajanta Offset and Packagings Limited; 2000:277 Available on: http://dhsprogram.com/pubs/pdf/ frind2/frind2.pdf.

26. Micronutrient Initiative. Summary Report: Iodized Salt Coverage Study 2010 Conducted across Eight States in India Government of India: The office of the salt commissioner; 2010 Available on: https://www.nutritionintl.org/content/user_files/2011/06/ india-salt-coverage-report-2010.pdf.

27. National Family Health Survey_2 (1998 - 99). International Institute for Population Sciences (IIPS) and ORC Macro 2000. Mumbai, India: IIPS; 1999 Available on: http:// dhsprogram.com/pubs/pdf/frind2/frind2.pdf.

28. National Family Health Survey. 2005 - 06 India International Institute for Population Sciences (IIPS), M International. vol. I. Mumbai: National Family Health Survey
(NFHS-3); 20002007 IIPS. Available on: http://rchiips.org/nfhs/NFHS-3\%20Data/ VOL-1/India_volume_I_corrected_17oct08.pdf.

29. Kumar S. Indicators to monitor progress of national iodine deficiency disorders control programme (NIDDCP) and some observations on iodised salt in West Bengal. Indian J Publ Health. 1995;39(4):141-147 PMID: 8690501.

30. Misra S, Kantharia SL, Damor JR. Prevalence of goiter in $6-12$ years school going children of Panchmahal District in Gujarat, India. Indian J Med Res. 2007;126:475-479 PMID: 18160754.

31. World Health Organization. Recommended Iodine Levels in Salt and Guidelines for Monitoring Their Adequacy and Effectiveness. WHO/NUT/96.13 Nutrition Unit. Geneva: Division of Food and Nutrition, WHO; 2007 Page No: 1-12. Available on: http://apps. who.int/iris/bitstream/10665/63322/1/WHO_NUT_96.13.pdf?ua = 1 .

32. MBI KIT: Field Testing Now Easier. MBI KITS international, Chennai, India. Available on: http://www.mbikits.com/the-mbi-kit/. 